\title{
FAILURE RISK CONTROL METHOD IN PROVIDING TECHNICAL SAFETY OF TRANSPORTATION ENGINEERING VEHICLE OPERATION FOR RECLAMATION WORK
}

\author{
Nadezhda Sevryugina, Alexey Apatenko \\ Russian Timiryazev State Agrarian University, Russia \\ nssevr@yandex.ru
}

\begin{abstract}
Analytical studies show that the vehicle performance characteristic aspects considerably impact the efficiency of service and operating entities, though these vehicles are of the same kind. These studies put emphasis on working efficiency of transportation engineering vehicles used for reclamation work. Integration of systems for safe vehicle operation in technological vehicle structure is substantiated. The need to develop not only functionality, but safety and performance capability of technological vehicles as well is emphasized. The brake system of a transportation engineering vehicle is taken as an example for practical substantiation of theoretical researches. The goal of the research: substantiate scientific multimodal approach to solution of control tasks for technical state and operation safety of transportation and engineering vehicles by means of predictive failure risk control, by the example of operating analysis of a brake system of a transportation engineering vehicle. Multimodal approach is proposed for solution of failure risk tasks concerning the vehicle and mechanism technical system by means of basic mathematical modeling theories, Taylor expansion and infogram construction on the basis of basic Boolean algebra provisions. It is suggested that for the system operability description it is necessary to assess the technical performance variation with consideration of the previous impact factors. A mathematical model of parameter variation intensity in form of Taylor expansion is presented. A three-parameter system model is taken as an example. The system failure risk detection task is solved by construction of Boolean functions. It is suggested to record logical links of technical system elements considering their conjunction, inversity and disjunction. A parametric structural model is designed for resource calculation and failure risk detection in the element base of a certain unit of transportation vehicles. The brake system is used as an example. The proposed theoretical and working models substantiate the multimodal approach potential. Multimodal approach contemplates science and practice integration for development of techniques and forecast assessment models of transportation and engineering vehicle technical state.
\end{abstract}

Keywords: operation, vehicles, failure risk, safety.

\section{Introduction}

Operation of transportation and engineering vehicles by the consumer should be not only efficient, but safe as well. Manufacturers integrate various security systems in vehicle structures. The brake system is one of the most important security systems.

Goal of the research: to substantiate scientific multimodal approach to provide technical state monitoring and safe operation of transportation and engineering vehicles by predictive failure risk control. The substantiation is based on operating analysis of the brake system of a transportation engineering vehicle.

The following tasks were solved to achieve the goal:

- structural perfection assessment of a pneumatic brake system taking into account operating load on the element base during reclamation works;

- substantiation of multimodal approach for development of a scientific support model of vehicle technical safety level variation control;

- development of failure risk assessment techniques in structural elements, eliminating dangerous situations for humans and environment.

Issues of the brake system structural efficiency continue to be relevant not only for manufacturers, but for services maintaining the vehicle operability as well $[1 ; 2]$.

Brake system reliability, and hence fail-safety and security is provided by structural perfection, compliance with the manufacturer's requirements on operating conditions, proper fulfillment of maintenance operations, and quality repair in the event of failure.

It is common knowledge that the brake system type is determined by the weight load on undercarriage. This parameter specifies basic gearing structures: brake systems with hydraulic and pneumatic drive of operating brake units $[3 ; 4]$. 
Condition monitoring of brake systems in vehicles used for reclamation work solves complex tasks, in particular: vehicle operating and technical safety support; implementation of a failure risk prediction mechanism in structural elements; elimination of dangerous situations for humans and environment [5-7].

A. P. Kuznetsov and others in [8] conducted research in the field of resource saving, developed an energy-informational model with a basic criterion - the efficiency coefficient of the mechanical system functioning.

In this context, the results are obtained on the development of a mechanism for managing technological changes, conducted by Hsin-Hui Chou and Judy Zolkiewski [9].

Niko Siltala, Eeva Järvenpää, Minna Lanz justify that an integral part of the resource assessment is the concept of executable capabilities, which describes the resource management interface in a vendor-neutral form [10].

S. I. Chalaganidze, J. B. Katsitadze, and G. G. Kutelia show the importance of reliability for agricultural machinery that operates in harsh soil-climatic and dynamic conditions, in contrast to some other industrial machines and equipment [11].

Brake system design solutions providing technical safety of vehicles. Standard design of air-brake control for transportation and engineering vehicles consists of a compression unit, air pressure control and regulating unit, pneumatic drive, pressurized air storage receiver, and other distributing gears. Power supply units support operating pressure in the range of 0.7-1.2 $\mathrm{MPa}$ (low pressure) and 1.4$2.0 \mathrm{MPa}$ (high pressure) in the brake system of transportation and engineering vehicles with dimension capacity and load-carrying capability above $3.5 \mathrm{~T}[1 ; 3]$.

Dual-braking system is the standard European version. One line (supply line) is connected to receivers of a pull tractor and a trailer or a semitrailer. This line is always pressurized. The second line (braking line) goes from the trailer control valve on a pull truck to the brake system valve of the trailer. If the supply line is damaged, the trailer braking valve actuates and brakes the trailer.

Safe operation rules make provisions for fixed pressure drop value when the vehicle engine is out of work, and also for leak limitation during operation.

Automatic unit for brake power regulation (ALB) is an important element of the brake system. It controls metrological parameters and limits the brake power value providing perfect distribution level and preventing from premature locking of real axle wheels.

\section{Materials and methods}

Theory of multimodal approach for failure risk assessment of units and mechanisms providing vehicle technical safety. Analytic researches of key scientists concerned with assessment of the technical system parameter variation show that typical mathematical models are set up to obtain calculation formulas containing constant values of correction factors $[3 ; 12 ; 13]$. To describe the system operability it is necessary to assess parameter variation during a specific period of vehicle operation, with consideration of the imposed previous impact factors. To get prognostic analysis it is necessary to specify the parameter variation intensity in terms of correction factors $[6 ; 13]$.

In general form these provisions are represented by a mathematical model of Taylor expansion. The example for a three-parameter model is given. Logical links of elements are recorded according to the following rule: from knowledge of the technical system as a system of various functionally related elements, let us write them as a set $F$ with the dependent parameter $f$ domain, in which every set element corresponds to a certain element $X$, which represents the domain of the independent variable $x: X=F=\{0,1\}$.

Parameter values of the dependent function $f$ are determined by variables and logical links between them. It is proved in theoretical terms that every Boolean function can be expanded in Taylor's series of the form:

$$
f(a)+\frac{f^{\prime \prime}(a)}{1 !}(x-a)+\frac{f^{\prime \prime}(a)}{2 !}(x-a)^{2}+\ldots
$$

where $f(a)$ - value of function $f(x)$ at $a$; 


$$
\begin{aligned}
& f^{\prime}(a) \text { - value of first-order derivative at } a \text {; } \\
& f^{\prime \prime}(a) \text { - value of second-order derivative at } a \text { and so on. }
\end{aligned}
$$

Conventions used. Let us translate the correction factors into dimensionless form of parameter variation with the range $0 \ldots 1$, which characterizes the parameter system compatibility at value 0 , and value 1 , at parameter variation to the critical level and failure risk possibility.

Initial three-parameter function is written as: $f(A ; B ; C)$.

Function expansion in variables for variable $A$ :

$$
f(A ; B ; C)=f\left(c_{1}, B, C\right) \oplus\left(A \oplus c_{1}\right) \frac{\partial f(A, B, C)}{\partial A},
$$

where $c_{1}$-constant value, with variation range from 0 to 1 for the system element, in prescribed function, parameter $A$ variation.

$A \oplus c_{1}-$ correction factor for functionality parameter variation estimation on a real-time basis.

Parameter $A$ variation considering constant correction value influences on every function element, which results in system mathematical transformation in functions $\psi_{i}$ :

$$
\psi_{1}=f\left(c_{1}, B, C\right), \psi_{2}=\frac{\partial f(A, B, C)}{\partial A} .
$$

These expressions describe variation of one parameter $A$, which calls single-parameter modeling. Model transfer to a double-parameter level requires function $\psi_{i}$ expansion in the following impact parameter, in the example in question - in variable $B$ :

$$
\psi_{1}=f\left(c_{1}, c_{2}, C\right) \oplus\left(B \mid \oplus c_{2}\right) \frac{\partial f\left(c_{1}, B, C\right)}{\partial B} ; \psi_{2}=\frac{\partial f\left(A, c_{2}, C\right)}{\partial A} \oplus\left(B \oplus c_{2}\right) \frac{\partial^{2} f(A, B, C)}{\partial A \partial B},
$$

where $c_{\mathrm{s}}-$ constant value, with variation range from 0 to 1 for the system element, in prescribed function, $B$ parameter variation.

$B \oplus c_{2}$ - correction factor for actual parameter value estimation in function $f(A ; B ; C)$.

Mathematical model of impact estimation on the variation system of two parameters becomes:

$$
\begin{gathered}
f(A, B, C)=f\left(c_{1}, c_{2}, C\right) \oplus\left(B \oplus c_{2}\right) \frac{\partial f\left(c_{1}, B, C\right)}{\partial B} \oplus\left(A+c_{1}\right)\left[\frac{\partial f\left(A, c_{2}, C\right)}{\partial A} \oplus\left(B \oplus c_{2}\right) \frac{\partial^{2} f(A, B, C)}{\partial A \partial B}\right]= \\
=f\left(c_{1}, c_{2}, C\right) \oplus\left(B \oplus c_{2}\right) \frac{\partial f\left(c_{1}, B, C\right)}{\partial B} \oplus\left(A \oplus c_{1}\right) \frac{\partial f\left(A, c_{2}, C\right)}{\partial A} \oplus\left(A \oplus c_{1}\right)\left(B \oplus c_{2}\right) \frac{\partial^{2} f(A, B, C)}{\partial A \partial B} .
\end{gathered}
$$

Further studies suggest considering level transition of the system for certain operating periods, including in particular the impact of two parameter variation on the system in general, and suggest correction factor introduction:

$$
\varphi_{1}=f\left(c_{1}, c_{2}, C\right), \varphi_{2}=\frac{\partial f\left(c_{1}, B, C\right)}{\partial B}, \varphi_{3}=\frac{\partial f\left(A, c_{2}, C\right)}{\partial A}, \varphi_{4}=\frac{\partial^{2} f(A, B, C)}{\partial A \partial B} .
$$

Mathematical model for three-parameter analysis, variable $C$, becomes:

$$
\begin{gathered}
f(A, B, C)=f\left(c_{1}, c_{2}, c_{3}\right) \oplus\left(C \oplus c_{3}\right) \frac{\partial f\left(c_{1}, c_{2}, C\right)}{\partial C} \oplus \\
\oplus\left(B \oplus c_{2}\right) \frac{\partial f\left(c_{1}, B, c_{3}\right)}{\partial B} \oplus\left(B \oplus c_{2}\right)\left(C \oplus c_{3}\right) \frac{\partial^{2} f\left(c_{1}, B, C\right)}{\partial B \partial C} \oplus \\
\oplus\left(A \oplus c_{1}\right) \frac{\partial f\left(A, c_{2}, c_{3}\right)}{\partial A} \oplus\left(A \oplus c_{1}\right)\left(C \oplus c_{3}\right) \frac{\partial^{2} f\left(A, c_{2}, C\right)}{\partial A \partial C} \oplus \\
\oplus\left(A \oplus c_{1}\right)\left(B \oplus c_{2}\right) \frac{\partial f^{2}\left(A, B, c_{3}\right)}{\partial A \partial B} \oplus\left(A \oplus c_{1}\right)\left(B \oplus c_{2}\right)\left(C \oplus c_{3}\right) \frac{\partial^{3} f(A, B, C)}{\partial A \partial B \partial C} .
\end{gathered}
$$


where $c_{3}-$ constant value, with variation range from 0 to 1 for the system element, in prescribed function, $C$ parameter variation.

This example demonstrates three-parameter modeling, $f(A ; B ; C)$ function Taylor expansion.

Further work with the model requires inversive analysis of the obtained factors.

Stable system functioning with three-parameter diagnostic is characterized by inversion-free correction factors: $c_{1}=c_{2}=c_{3}=0$.

Critical deviation parameter achievement in the model is represented in a form:

$$
f=f\left(A_{i}=c\right) \oplus\left(A_{i} \oplus c\right) \frac{\partial f}{\partial A_{i}}, \text { at } c \in\{0,1\},
$$

If $c=0$, then

$$
f=f\left(A_{i}=0\right) \oplus\left(A_{i}\right) \frac{\partial f}{\partial A_{i}} ;
$$

and at $c=1$

$$
f=f\left(A_{i}=1\right) \oplus\left(\overline{A_{i}}\right) \frac{\partial f}{\partial A_{i}} .
$$

Alongside with analytical construction, the multimodal model can take the form of a compliance truth table. In this case, to solve the failure risk detection task by Boolean functions formulation, it is necessary to record logical links of the technical system elements, taking into account their conjunction, inversity and disjunction [14].

Hierarchically the technical system can be represented by various functionally-connected elements.

For $F$ set with the dependent parameter $f$ domain, every set element corresponds to a certain element $X$, which represents the domain of the independent variable $x: X=F=\{0,1\}$.

Parameter values of the related function $f$ are determined by variables and logical links between them.

Let us specify a condition that every function consists of one conjunction of arguments, inversive or noninversive. At that, inversion distribution is in strict compliance with distribution on zeroes in binary notation of the set, in which the function has unit value. The three-parameter function concerned specifies the dependence of arguments $A, B, C$.

It is assumed that the parameter in vector form is the inversion of a basic value, i.e. parameter $A$ corresponds to inversion in the form of $A$, and for calculation at $A=1$, the inversive value " 0 " is taken respectively.

\section{Results}

Practical application of a multimodal approach. Transportation engineering vehicles for reclamation work are operated in conditions deviating from normal by humidity and application severity factors, dust content, on cross-country terrain, which impact on performance degradation and technical safety violation $[7 ; 13]$.

Parametric structural model is designed for resource calculation and forecast failure risk detection in the element base of a certain unit of the transportation engineering vehicle. The task card specifies metrological values of operating parameters, permissive tolerance and variation conditions, i.e. wear properties [3; 12].

Metrological control of the brake system for drum type wheel brakes is provided by means of the parameter: brake factor $\left(C^{*}=C_{\text {primary shoe }}+C_{\text {econdary shoe }}\right)$, which is an evaluative one for the brake-toaction force ratio. It should be noted that this value is affected by braking gear ratio, and the friction coefficient, which depends on velocity, braking pressure and temperature (Fig. 1). 

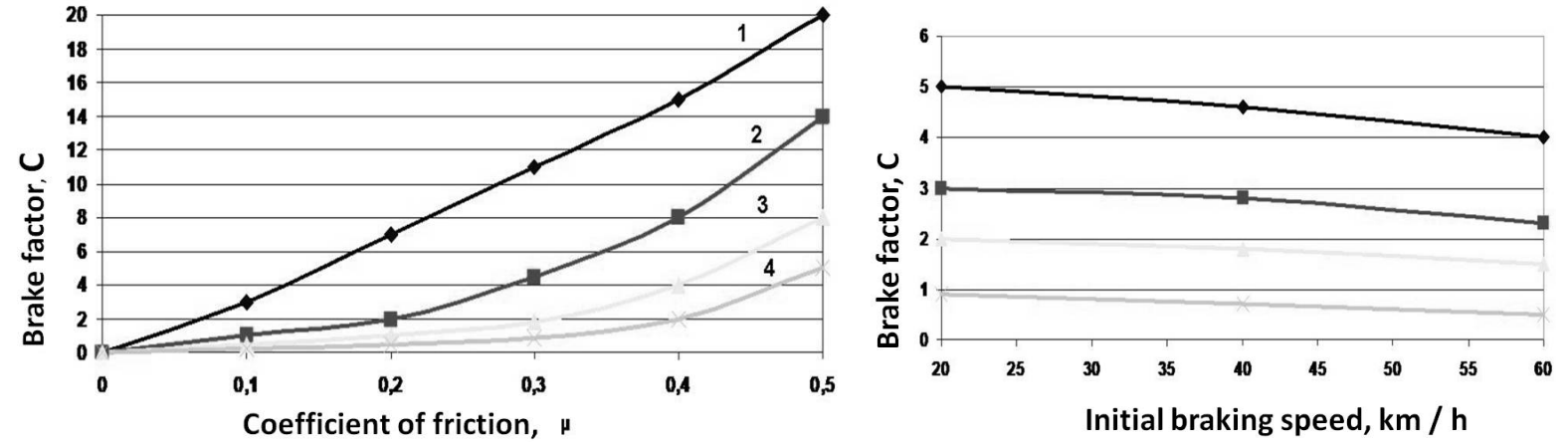

Fig. 1. Three-parameter analysis: infogram of brake coefficient $C^{*}$ variation as a function of friction coefficient and initial braking speed: 1 -drum brake with self-energizing action; 2 - dumplex drum brake with floating shoes; 3 - simplex drum brake; 4 - disc brake

The friction coefficient taken as $\mu=0.38$ is the basic value for the brake coefficient definition in a simplex drum brake, and the brake-to-drive force ratio is taken as $\sim 2$.

This structure has a disadvantage from a metrological point of view: considerable braking effort difference in two braking shoes results in increased wear of the primary shoe lining $C_{\text {primary shoe, as }}$ compared to closing brake shoe $C_{\text {secondary shoe }}$.

At present, the disc brake is the preferred structure, as it is designed for transportation engineering vehicles having average and high load-carrying capacity. Brake disc plates are less sensitive to damages than drum brakes. The brake coefficient is equal to $C^{*}=0.76$, at basic value $\mu=0.38$.

Electronic brake control system (ELB) allows motive and braking forces optimization in transportation engineering vehicles. ELB control is based on additional information, the system is connected with area network controller (CAN) to provide connection between the ELB system and electronic control unit ECU of the braking system and pressure modulator valves. Electronic control unit ECU has a wide program for failure detection within the whole system range. All wheels equipped with ELB decelerate simultaneously. Temperature strains and braking mechanism wear are balanced, tyre grip is optimized.

When the parameters deviate from the values specified by the manufacturer, and failure in service is detected, the block disconnects the faulty subsystem and generates a code containing detailed failure record. This code can be sent to the repair shop. ECU unicity is in automatic adaptation to different models of transportation engineering vehicles [14-16].

\section{Discussion}

Studies of many scientists and manufacturers' design departments are devoted to failure risk detection in systems providing safety of transportation engineering vehicles in general, but, as experience has shown, joining efforts allow obtaining significant results and long-term perspective, what is more important.

Multimodal approach contemplates science and practice integration for development of techniques and forecast assessment models of transportation and engineering vehicle technical state $[15 ; 17 ; 18]$.

Research (Frans Prenkert, Nina Hasche, Gabriel Linton) highlights the consistency of the analytical structure, recognizing the empirical variability of resource interfaces along with consistent conceptualization of resources [19], which is consistent with the work of the leading Russian scientists V. A. Zorin and N. I. Baurova, who introduce the basic provisions of the theory of catastrophes into the analytical apparatus for evaluating the resource of a technical system [20].

\section{Conclusions}

1. It is suggested to assess the technical state changes with consideration of the imposed previous impact factors during operation to describe the system operability.

2. A mathematical model of parameter variation intensity in form of Taylor expansion is presented. The three-parameter system model is taken as an example. 
3. To improve efficient operation of transportation engineering vehicles, it is recommended to scale up the electronic brake control system (ELB) use in vehicles, by up-to-date digital technologies integration.

\section{References}

[1] Apatenko A.S., Sevryugina N.S. Digital systems and accuracy of capability control of technological vehicles in environmental engineering. Agricultural machinery and equipment Journal, vol. 7, 2019, pp. 35-38.

[2] Baurova N.I., Zorin V.A., Prikhodko V.M. Informational model of technical system state. All materials. Encyclopedic guide, vol. 6, 2017, pp. 11-16.

[3] Bogomolov A.A , Bunin M.V and Sevryugina N.S. Structure and semantics of a variational optimization of transport machines and technological processes in General systems theory: a monograph (Belgorod: Publishing house BGTU), 2009, 83 p.

[4] Goropashnaya A.V. The assessment of the importance of non-monotonic arguments of Boolean functions in logical-probabilistic safety analysis of complex technical systems, Ser 10, vol. 1 (Herald of St. Petersburg University), 2009, pp. 19-32.

[5] Grib V.V., Zorin V.A., Zhukov A.N. Multi-Criteria assessment of the technical condition of mechanisms and machines (dynamics and wear) Journal of Repair. Recovery. Modernization, vol. 6, 2016, pp. 19-22.

[6] Dunichkin I.V., Kovaleva A.S., Tashlykova I.V. Approaches to the assessment of energy potential of renewable energy sources in the territory of Russia. Power equipment. Autonomous system, vol. 1, 2018, pp. 15-27.

[7] Kirichenko I.G. Modular design concept for constructional technological vehicles. - Kharkov, HNADU Publishing, 2002, 119 p.

[8] Kuznetsov A.P., Blau P., Koriath H.-J., Richter M. Criteria for Energy-efficiency of Technological Processes, Technological Machines and Production Engineering, Procedia CIRP, vol. 46, 2016, pp. 340-343, DOI: 10.1016/j.procir.2016.04.002.

[9] Chou H.H., Zolkiewski J. Managing resource interaction as a means to cope with technological change, Journal of Business Research, Vol. 65, Issue 2, 2012, pp. 188-195, ISSN 0148-2963, https://doi.org/10.1016/j.jbusres.2011.05.021.

[10] Siltala N., Järvenpää E., Lanz M. An Executable Capability Concept in Formal Resource Descriptions, This research has received funding from the European Union's Horizon 2020 research and innovation programmed under grant agreement No. 680759 ReCaM. http://www.recam-project.eu, IFAC-Papers On Line, vol. 51, Issue 11, 2018, pp. 102-107, DOI: $10.1016 /$ j.ifacol.2018.08.242

[11] Chalaganidze S.I., Katsitadze J.B., Kutelia G.G. The theoretical and experimental study of the ploughs' ploughs hare sin order to in crease the reliability of resource-saving technology using similarity and dimensions theory, Annals of Agrarian Science, vol. 15, Issue 3, 2017, pp. 329-331, https://doi.org/10.1016/j.aasci.2017.05.024.

[12] Verigin Y.A., Tolstenev S.V. Synergetic basics of processes and technologies, Barnaul: AltSTU, 2007, $160 \mathrm{p}$.

[13] Universal programmable controller Can Log series P. Certificate. Operation manual. Remote access point. http://www.canlog.ru/files/pasport_canlog.pdf Access: 25.10.2018.

[14] Chulkov V.O., Griph M.I., Kazaryan R.R., Masturov I.Y., Smirnov P.N. Health and wellness. Organizational and anthropotechnical reliability of functional systems in mobile environment of construction manufacturing, Moscow: ASV publishing House. 2003, 176 p.

[15] Sevryugina N. Modified Method for Calculation of Vehicles Residual Lifetime with Regard of the Impact Factors Variability. 2018. Advances in Intelligent Systems and Computing. vol. 692, pp. 273-281 DOI: 10.1007/978-3-319-70987-1_29

[16] Poddaeva O., Kubenin A., Gribach D. Measures of Improving the Accuracy of the Calculation of Energy Efficiency and Energy Saving of Construction Transport Infrastructure, 2018, Advances in Intelligent Systems and Computing, vol. 692, pp. 490-497. DOI: 10.1007/978-3-319-70987$1 \_52$

[17] Apatenko A. S. Sevryugina N. S. Methods of recruiting of mobile repair services and maintenance of machines performing reclamation works IOP Conference Series: Materials Science and 
Engineering, Vol. 786, International Scientific Conference Interstroymeh - 2019 (ISM - 2019), Kazan, Russian Federation https://doi.org/10.1088/1757-899X/786/1/012037

[18] Coccia M., Watts J. A theory of the evolution of technology: Technological parasitism and the implications for innovation management, Journal of Engineering and Technology Management, Volume 55, 2020, 101552, ISSN 0923-4748, DOI: 10.1016/j.jengtecman.2019.11.003.

[19] Prenkert F., Hasche N., Linton G. Towards a systematic analytical frame work of resource inter faces, Journal of Business Research, vol. 100, 2019, pp. 139-149, ISSN 0148-2963, DOI: 10.1016/j.jbusres.2019.03.027.

[20]Zorin V., Baurova N. Assessment of means of mechanization of construction risks using catastrophe theory 2018 MATEC Web of Conferences, vol. 251, 2018. VI International Scientific Conference "Integration, Partnership and Innovation in Construction Science and Education" (IPICSE-2018) https://doi.org/10.1051/matecconf/201825103008 